\title{
TESTING VISUAL SPECIES RECOGNITION IN PRECIS (LEPIDOPTERA: NYMPHALIDAE) USING A COLD-SHOCK PHENOCOPY
}

\author{
By Arthur M. Shapiro' \\ Department of Zoology, University of California \\ Davis, California 95616
}

There have been many studies of the role of color and pattern in mating and species recognition in butterflies. For example, Crane (1955) manipulated the bold color pattern of Heliconius spp. (Heliconiidae), affecting mating success; Burns (1966) claimed on the basis of spermatophore counts that differential attractiveness of female morphs helped to maintain a mimetic polymorphism in Papilio glaucus L. (Papilionidae); and Silberglied, Aiello, and Lamas (1980) found that modifying the pattern of Anartia (Nymphalidae) affected mating success but not survivorship.

Recently Hafernik (1983) demonstrated that the conspicuous pale dorsal forewing band serves as a visual species-recognition character, contributing to reproductive isolation between the partly sympatric buckeye butterflies Precis (=Junonia) coenia Hubner and $P$. nigrosuffusa (Barnes \& McDunnough). In hybridization experiments these entities are quite compatible genetically and developmentally; Hafernik concluded that differences between them "are probably not associated with major genomic reorganization, but are rather the result of allelic differences at a few loci," including presumably those that control the presence or absence of the forewing band.

The experiments done by Hafernik to test the hypothesis of visual reproductive isolation were modeled on the work of Scott (1972), involving presentation of reared virgin females to wild patrolling males afield. There were four sets of experiments (i) actual combinations of nigrosuffusa and coenia; (ii) coenia painted to resemble nigrosuffusa; (iii) "wing transplants" (wings of one type glued onto the wings of a living animal of the other; (iv) paper models. All of these tended to indicate that coenia males discriminate against

'Manuscript received by' the editor January' 6, 1983 
bandless females, and that species-specific pheromones need not be invoked to account for reproductive isolation. None of Hafernik's females actually mated, but Scott (1972) showed that darkening the wings of male coenia does not lower their courting success with conspecifics, as it does when females are darkened.

Despite the consistency of these results, there are possibly confounded variables whenever one tests using entire genomes (as in i above, in which pheromonal and subtle behavioral cues cannot be controlled for), or altered phenotypes (as in ii and iii, where the "similarity" to the other species is questionable, and wing loading and odor may be altered by glues or paints). However, another test is available, not exploited by Hafernik: pure coenia genomes can be induced to produce nigrosuffusa-like phenotypes, which may then be presented to coenia males afield. This situation arises from the sensitivity of coenia to temperature shocks applied shortly after pupation.

A named aberration of coenia, "schraderi," figured in color by Comstock (1927, plate 43), resembles nigrosuffusa in lacking the band. Other characters, including the hindwing ocelli, are in the coenia rather than the nigrosuffusa state. Schrader's specimen was reared, but similar individuals do occur in nature. One shown in fig. If has the hindwing ocelli and distal pattern obsolescent; others are normal for these pattern elements. The actual frequency of bandless buckeyes is unknown. I have taken two at the same locality in eleven years, during which time I must have seen hundreds of thousands of individuals. No clear-cut genetic basis for bandlessness has been established, but the same phenotypes are readily inducible by subjecting wild California pupae to sustained low temperatures. Fig. 2 shows chilled individuals from three different families. The extensive variation in individual response to treatment is characteristic of such experiments. The involvement of the ocelli and distal pattern is partly controllable by age of the pupa at onset of chilling, but even very precise timing can only reduce, not eliminate, the variation. Such indeterminacy was characterized as early as 1913 in Pictet's "law of melanization and albinization of parts," which is a statement of the partial independence of different pattern-determining processes during wing development.

Several broods of pure coenia from Solano County, California were reared and subjected to a potent cold-shock treatment ( 3 weeks 


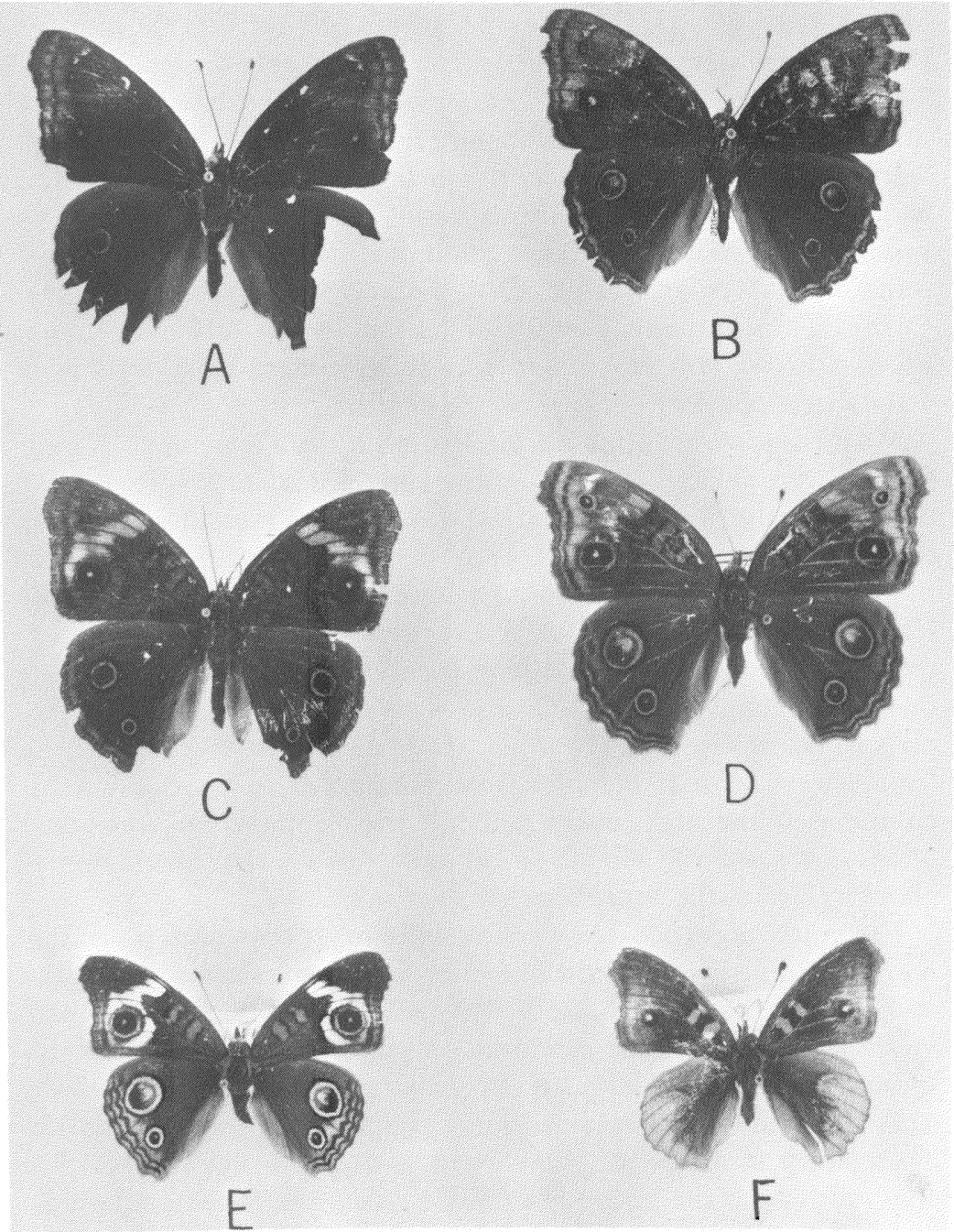

Fig. 1. Phenotypes of wild-collected Precis. A,C, male, B,D, female P. nigrosuffusa from Arizona, USA and Sinaloa, Mexico. E, normal female $P$. coenia, Solano Co., California. F. "schraderi", Suisun Marsh, Solano Co., CA. viii.28.1978. 
at $3^{\circ} \mathrm{C}$ beginning $8 \mathrm{hr}$ after pupation). The usual spectrum of phenotypic response was observed. About one-third of the animals which eclosed were seriously crippled and unusable for mating tests. The remainder - 46 females in toto-were classified into three more or less arbitrary phenotypic categories: (i) essentially unaltered (fig. 2e), (ii) bandless but with ocelli unaltered (figs. 2a-d), and (iii) bandless and with ocelli obsolete (fig. 2f). These were used in experiments modeled on Scott's and Hafernik's, carried out on a total of 9 days at Suisun City, Solano County, and Rancho Cordova, Sacramento County, in urban vacant lots and annual grassland from late September to early November 1982. Wild male coenia were common throughout this period.

My methodology differed from Hafernik's in a few points. Virgin females were held, unfed and unflown, in the dark at $3^{\circ} \mathrm{C}$ for 3 to 11 days before use. This treatment did not diminish their attractiveness relative to Hafernik's females. They were transported in a cooler in the dark to the study sites and allowed to warm in the sun (air temperatures $14-24^{\circ} \mathrm{C}$ ). After a test they were usually recaptured, rechilled for at least $15 \mathrm{~min}$, and re-used. A few were lost, and about one-fourth mated successfully and were not re-used. As in Hafernik's work, only releases in which the male at least investigated the female were scored. Females were considered to have elicited a courtship if the male either attempted to copulate or remained oriented toward the female for at least $20 \mathrm{sec}$. The durations of about a third of the courtships were recorded.

The percentages courted were overall higher than seen by Hafernik. For Point Richmond, California female coenia $\times$ male coenia at Point Richmond, Hafernik had $64 \%$ courtship. When female nigrosuffusa from Texas were used, this dropped to $10 \%$. My corresponding figures (table 1) are $74 \%$ and (pooled classes ii and iii) $49 \%$. The difference remains highly significant, however, and the discrepancy in frequency may be due to differences in weather conditions or to the torpidity of my females. For timed courtships, bandless females elicited less persistence than banded ones, but the difference was not statistically significant. Most of the actual copulations were essentially instantaneous, regardless of phenotype.

This experiment does not rule out pheromones in Precis courtship, but as in previous work indicates that visual cues are impor- 


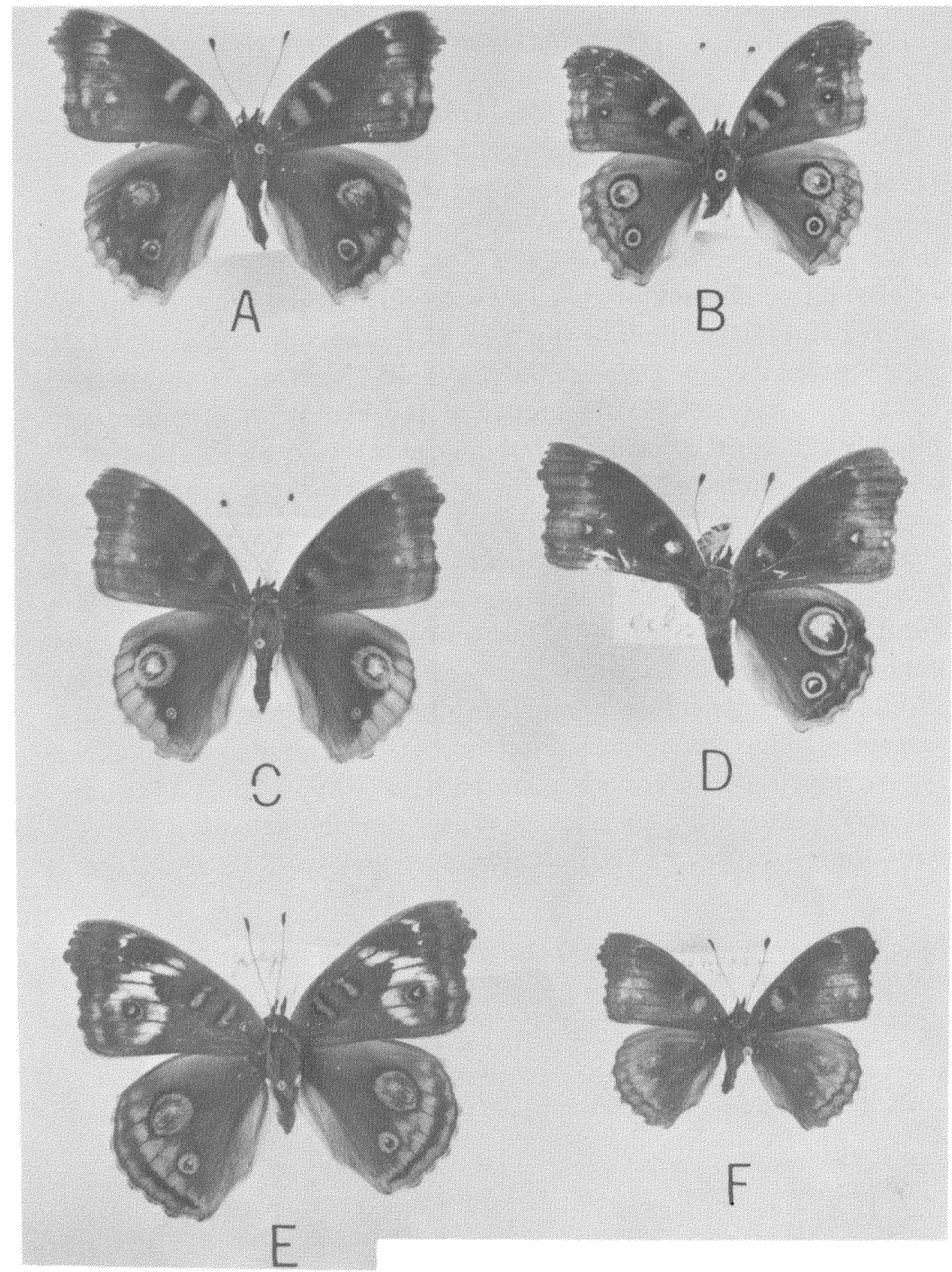

Fig. 2. Phenotypes of female $P$. coenia from northern California, induced by chilling the young pupa. A-D, grade ii (bandless, ocelli unaltered). E, grade $i$ (essentially unaltered). F, grade iii (bandless, ocelli obsolete). 
tant and possibly adequate to account for reproductive isolation. (It is conceivable that pheromones could be physiologically coupled to phenotypes such that the most phenotypically deviant females would also be pheromonally abnormal.)

The control of pattern in Precis has been studied by Nijhout $(1980 \mathrm{a}, \mathrm{b})$, who has shown that all of the wing pigments in $P$. coenia are melanins and that the ocelli are determined by well-defined foci in the early pupal wing. His work does not permit a causal analysis of how pupal chilling phenocopies the normal phenotype of nigrosuffusa, though the phenocopy "straw" has been linked functionally to its genocopy in Drosophila (Seybold, Meltzer, and Mitchell, 1975). In Shapiro's (1981) model of the evolution of phenotypic plasticity, a genetic basis for bandlessness could be established by selection of modifiers bringing the latent "schraderi" response to the surface under normal developmental temperatures. The derivative character of bandlessness is shown clearly by its variable penetrance (especially in females) in pure nigrosuffusa populations. But how did it become virtually fixed? Discrimination by male coenia against bandless females, even genotypicaly normal ones with intact wings, should lead to selection against any bandless allele, however originated. Under the conventional model for enhancement of prezygotic reproductive isolating mechanisms in secondary sympatry, one could rationalize bandlessness as a device protecting the gene pool of nigrosuffusa. This, however, presupposes a disadvantage to

Table 1. Success of cold-shocked female Precis coenia in attracting courtships by wild males in field tests in northern California.

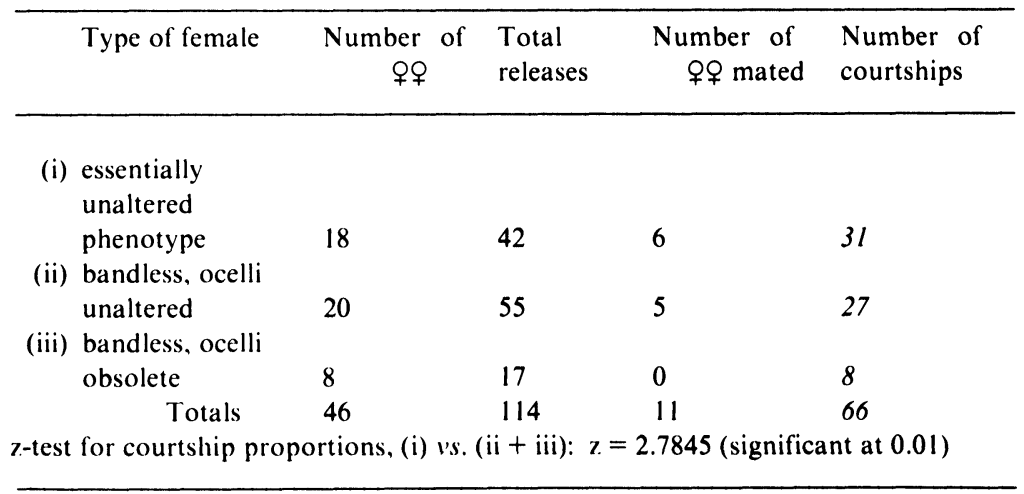


hybridization which outweighs the discrimination against bandless females, and no such disadvantage has been found. Bandlessness may be quite incidental to hybridization, but that still leaves the question of why it persists.

\section{ACKNOWLEDGEMENTS}

This research was supported by the Department of Zoology, UC Davis, to which I express my thanks. This paper is dedicated to the memory of Robert E. Silberglied, who would no doubt have had great fun with shock phenotypes in behavioral studies.

Burns, J. M.

\section{REFERENCES}

1966. Preferential mating v's. mimicry. Science 153: 551-553.

Comstock, J. A.

1927. Butterflies of California. Publ. by author, Los Angeles. 335 pp.

Crane, J.

1955. Imaginal behavior of a Trinidad butterfly, Heliconius erato hydara Hewitson, with special reference to the social use of color. Zoologica 40: 167-196.

HAFERNIK, J. E., JR.

1983. Phenetics and ecology of hybridization in buckeye butterflies (Lepidoptera: Nymphalidae). Univ. Calif. Pubs. in Ent., 96: 1-109.

Nisholit, H. F.

1980a. Pattern formation on Lepidopteran wings: determination of an eyespot. Devel. Biol. 80:267-274. 1980b. Ontogeny of the color pattern on the wings of Precis coenia (Lepidoptera: Nymphalidae). Devel. Biol. 80: $275-288$.

Pictet, A.

1913. Recherches expérimentales sur les mécanismes du mélanisme et de l'albinisme chez. les Lepidoptères. Mem. Soc. Physique et Hist. Nat. de Génève 27: 111-278.

Scott, J. A.

1972. Comparative mating and dispersal systems in butterflies. Unpubl. Ph.D. thesis, Univ. Calif. (Berkeley).

Seybold, W. D., P. S. Meltzer and H. K. Mitchell.

1975. Phenol oxidase activation in Drosophila: a cascade of reactions. Biochem. Genet. 13:85-108.

SHAPIRO, A. M.

1981. Phenotypic plasticity in temperate and subarctic Nymphalis antiopa (Nymphalidae): evidence for adaptive canalization. J. Lepid. Soc. 35: 124-131.

Silberglied, R. E., A. Aiello, and G. Lamas.

1980. Neotropical butterflies of the genus Anartia: systematics, life histories, and general biology (Lepidoptera: Nymphalidae). Psyche 86:219-260. 

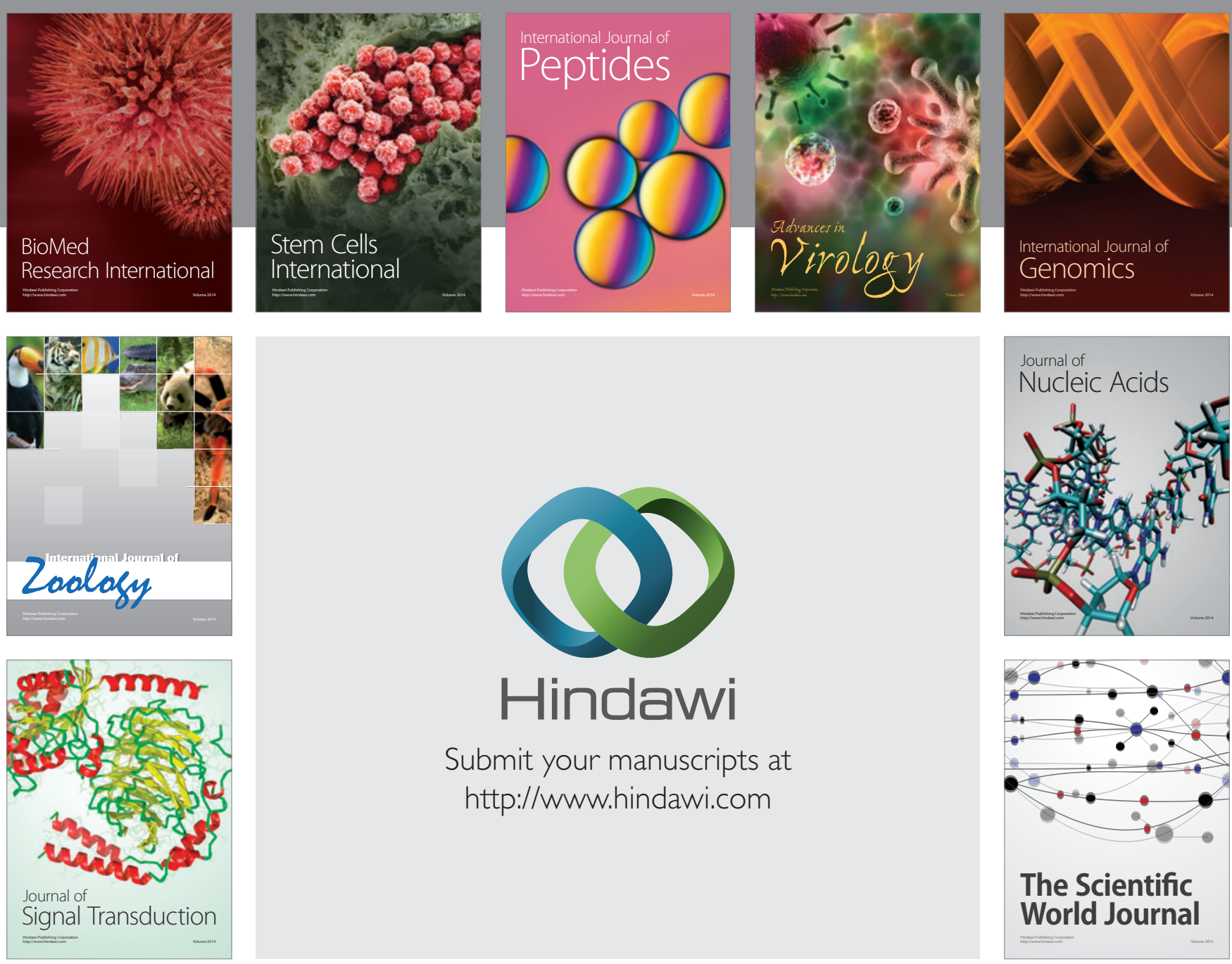

Submit your manuscripts at

http://www.hindawi.com
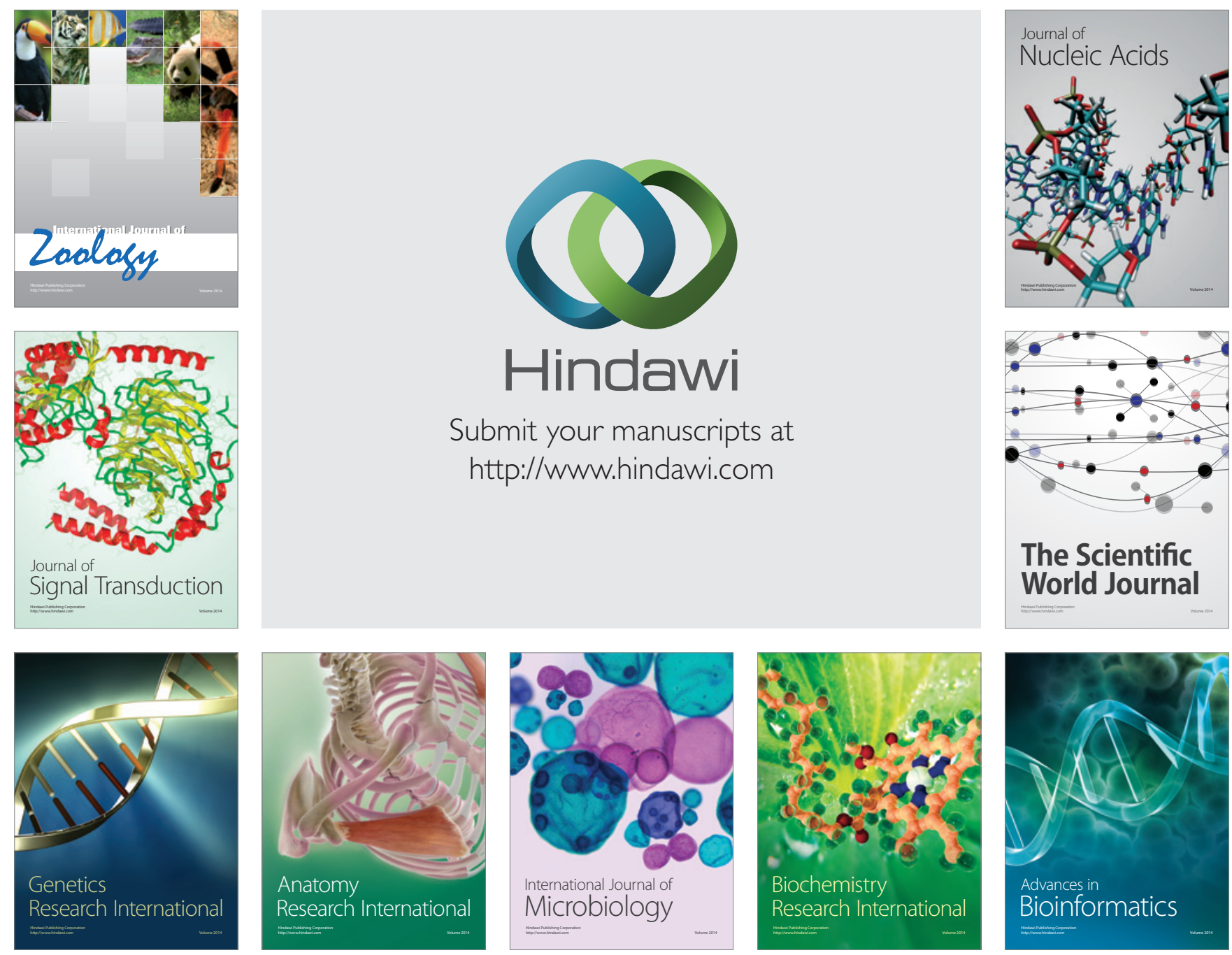

The Scientific World Journal
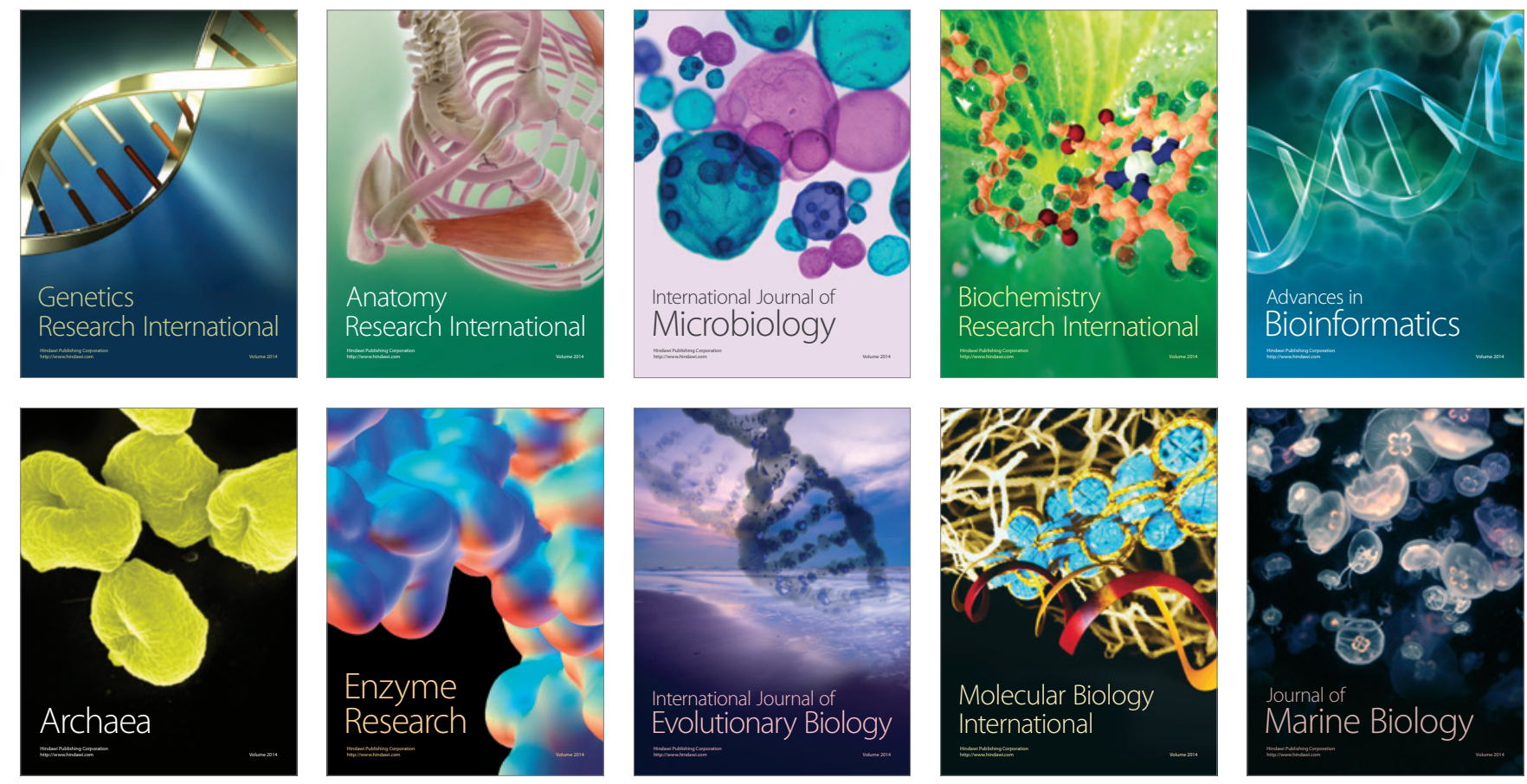